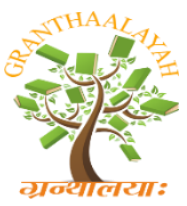

$$
\begin{gathered}
\text { INTERNATIONAL JOURNAL OF RESEARCH - } \\
\text { GRANTHAALAYAH } \\
\text { A knowledge Repository }
\end{gathered}
$$

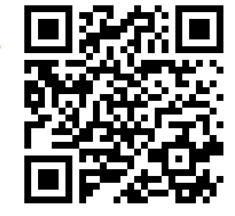

Science

\title{
PRIMARY ENERGY ACCUMULATION THROUGH ADVANCED GAS HYDRATES SYSTEM
}

\author{
Peter Durcansky ${ }^{*}$, David Hecko ${ }^{1}$, Milan Malcho ${ }^{1}$ \\ ${ }^{1}$ University of Žilina, Faculty of Mechanical Engineering, Department of Power Engineering, \\ Univerzitna 1, 01026 Žilina, Slovakia
}

\begin{abstract}
Accumulation of primary energy of natural gas is a perspective industrial area mainly for countries dependent on the import of energy and raw materials. Transporting and storage of natural gas is economically and technologically demanding, which is always reflected in the resulting price. Natural gas hydrates allow transport and storage at low pressures and relatively favorable temperatures. Another no less important area is the storage of energy in biogas plants where gas formation is time-dependent. Biogas hydrates would allow short-term storage at room temperature and atmospheric pressure. This article deals with the design of a functional prototype for the production of hydrates and numerical simulation.

Keywords: Primary; Energy; Accumulation; Hydrates System.

Cite This Article: Peter Durcansky, David Hecko, and Milan Malcho. (2019). "PRIMARY ENERGY ACCUMULATION THROUGH ADVANCED GAS HYDRATES SYSTEM." International Journal of Research - Granthaalayah, 7(5), 278-283. https://doi.org/10.29121/granthaalayah.v7.i5.2019.846.
\end{abstract}

\section{Introduction}

\section{Gas Hydrate as Energy Storage}

The storage of natural gas in hydrates is particularly advantageous in terms of storage capacity, but also in terms of gas storage safety, which is possible at higher temperatures and lower pressures compared to other storage technologies such as liquefaction or compression. The gas hydrate can be a great source of energy that begins to be included in the considerations of gas supply for the next decades. It is estimated that $99 \%$ of the global gas hydrate supply occurs in marine sediments under the corresponding temperature and pressure conditions, in seabed sediments, at depths from $300 \mathrm{~m}$ to $4000 \mathrm{~m}$. [1, 2] 


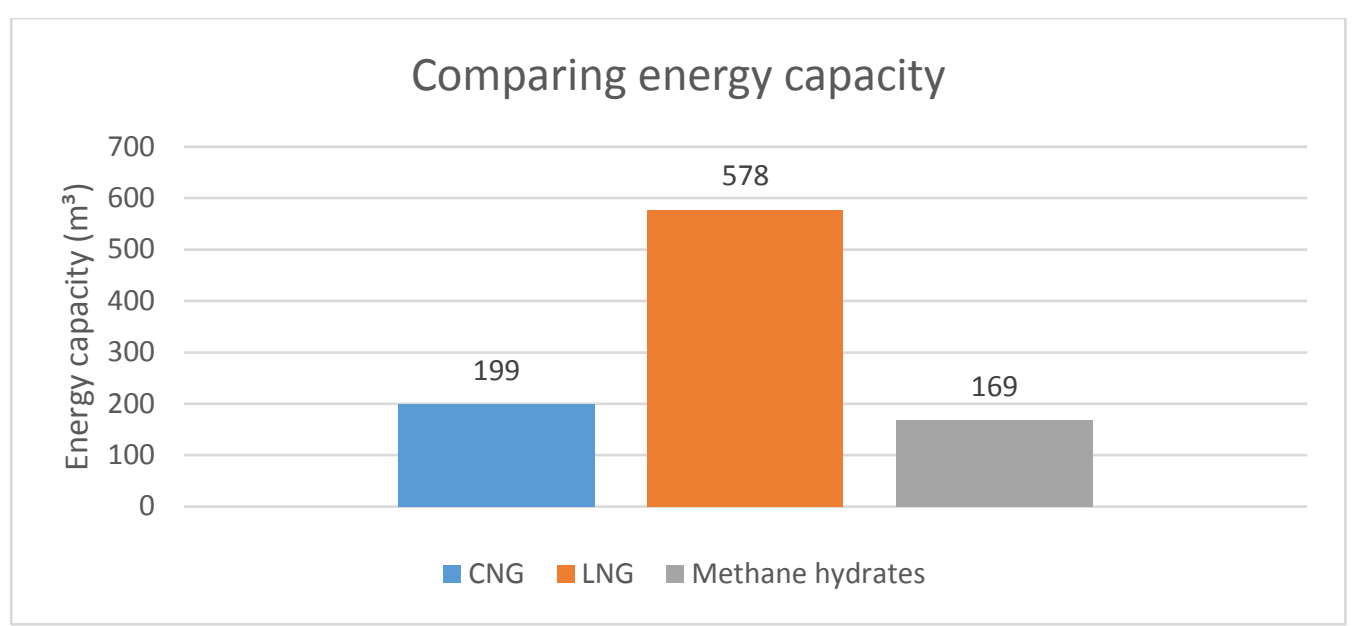

Figure 1: Comparing energy capacity

The gas hydrate can be a great source of energy that begins to be included in the considerations of gas supply for the next decades. It is estimated that $99 \%$ of the global gas hydrate supply occurs in marine sediments under the corresponding temperature and pressure conditions, in seabed sediments, at depths from $300 \mathrm{~m}$ to $4000 \mathrm{~m}$. The storage of natural gas energy by targeted hydrate formation under controlled conditions can provide long-term energy storage options in a convenient form for safe storage. However, the technology of hydrate formation is also applicable to other gases, the storage of greenhouse gases into stable hydrate structures appears to be advantageous, thereby reducing the amount of emissions discharged into the environment.

Table 1: Schematic positions on the experimental equipment.

\begin{tabular}{|l|l|l|l|l|}
\hline & $\begin{array}{c}\text { Energy } \\
\left.\text { capacity } \mathbf{( m}^{\mathbf{3}}\right)\end{array}$ & $\begin{array}{c}\text { Specific energy } \\
\left(\mathbf{M J} \mathbf{k g}^{-\mathbf{1}}\right)\end{array}$ & $\begin{array}{c}\text { Energy density } \\
\left(\mathbf{M J m} \mathbf{m}^{-3}\right)\end{array}$ & $\begin{array}{c}\text { Energy input } \\
\left(\mathbf{k J k g} \mathbf{~}^{-\mathbf{1}}\right)\end{array}$ \\
\hline CNG & 198,81 & 48,95 & 6913,74 & 2429,58 \\
\hline LNG & 577,77 & 48,95 & 20092,67 & 907,89 \\
\hline $\begin{array}{l}\text { Methane } \\
\text { hydrates }\end{array}$ & 168,9 & 6,53 & 5879,5 & 416,35 \\
\hline
\end{tabular}

\section{Computational Methods}

Computational methods of hydrate formation are generally divided into methods based on phase equilibrium of chemical potentials and methods based on three-phase equilibrium liquid water hydrate - water vapor. The simplest methods include gas density determination. The advantage of this method is its simplicity, including only the graph. FIG. 2 is a plot of pressure versus temperature. The third parameter is the gas density. This can be easily calculated on the basis of the gas composition. The disadvantage of this method is its inaccuracy over experimental results. (Carroll, 1958)

Another method is to establish a balance based on phase diagrams for water, hydrocarbon and $\mathrm{CO} 2$. These diagrams differ considerably from normal hydrocarbon phase diagrams mainly due to the linkage of hydrogen and hydrocarbon bonds. 


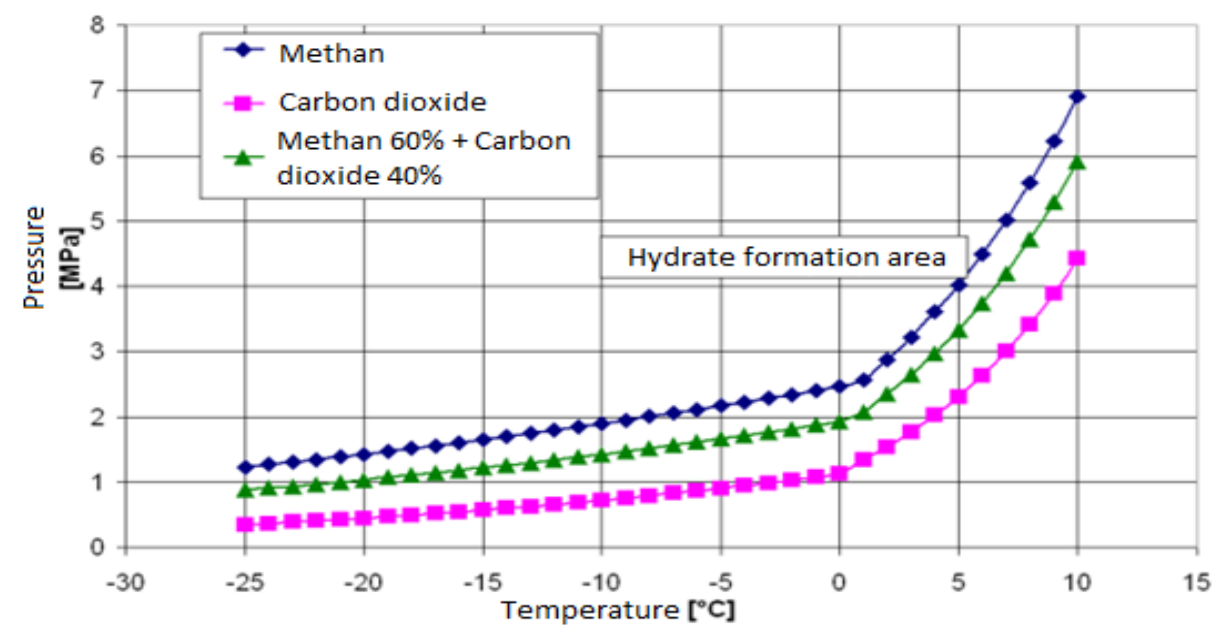

Graph 2: Diagram of methane hydrate, $\mathrm{CO}_{2}$ and their blend.

Graph. 2 shows the phase diagram of the individual gases. This method provides acceptable results for pure gases. However, it differs considerably from the fair values for mixtures. From these equilibrium it is clear that the presence of $\mathrm{CO}_{2}$ in the hydrocarbon gas shifts the balance of hydrate formation to higher temperatures and lower pressures. (Sloan, 2008)

A very important characteristic is also the time required for hydrate formation. The rate of hydrate formation is strongly influenced by temperature and pressure. While the time required to form hydrates at close to equilibrium conditions can be considerably long and can be as high as 24 hours, significant decreases in temperature formation or pressure build-up occur. An important criterion for determining the speed of creation is the so-called. the subcooling temperature (Tsubc), which is defined as the difference between the actual temperature and the equilibrium temperature of hydrate formation at a given pressure. Knowing the equilibrium temperature, the rate of hydrate formation can then be calculated using empirical equations, depending on the temperature of the undercooling. (Kim, 2009)

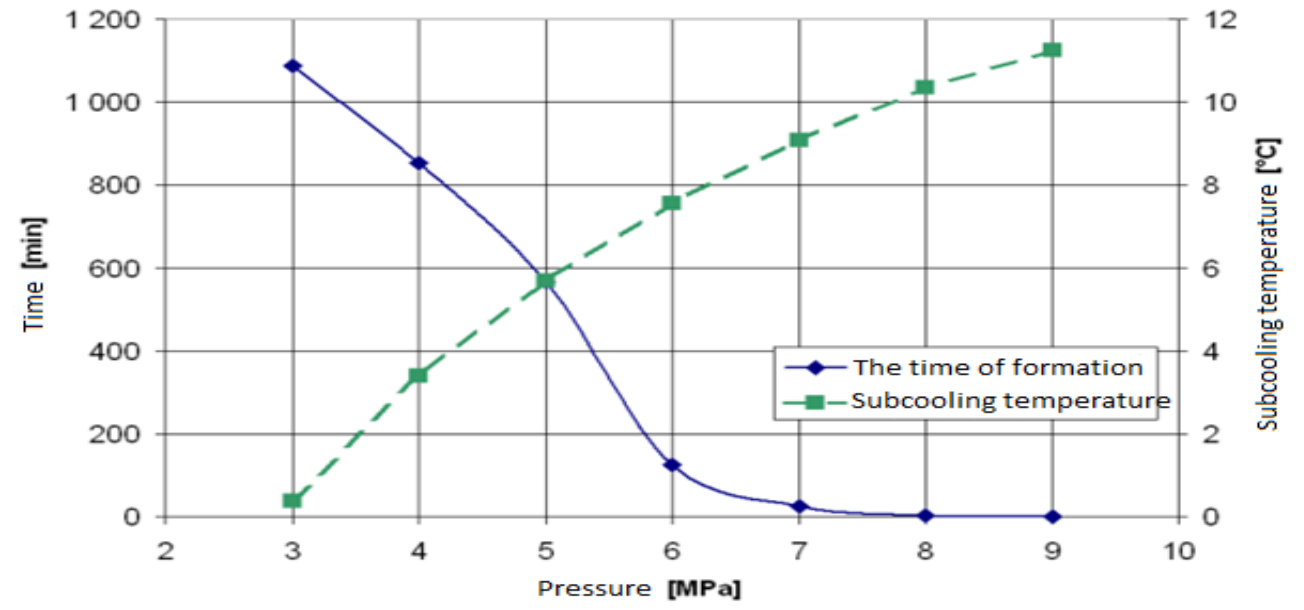

Graph 3: Dependence of hydrate on pressure at $1^{\circ} \mathrm{C}(\mathrm{Kim}, 2009)$. 


\section{Gas Hydrate Production Site Proposal}

The device is based on the knowledge of typical mechanisms of methane hydrate formation. Methane hydrate deposits are formed at sites where methane and water are located at temperatures and pressures that are favorable to hydrate formation. These conditions are most commonly found in marine sediments and arctic permafrost. The technique of rapidly and continuously generating gas hydrates in an economically efficient manner would necessarily merit increased attention and the necessary development and innovation of technology in this field. The following section of the article describes the experimental equipment with a projected pressure of $25 \mathrm{MPa}$, in which the necessary state variables are maintained to determine suitable parameters for the accumulation of gas into the hydrate structures. The experimental equipment was designed based on these temperature and pressure requirements, with temperature in range between $0^{\circ} \mathrm{C}$ to $20^{\circ} \mathrm{C}$ and pressure at approx. $25 \mathrm{MPa}$. A diagram of an experimental device for generating methane hydrates with individual elements is shown in the following figure.

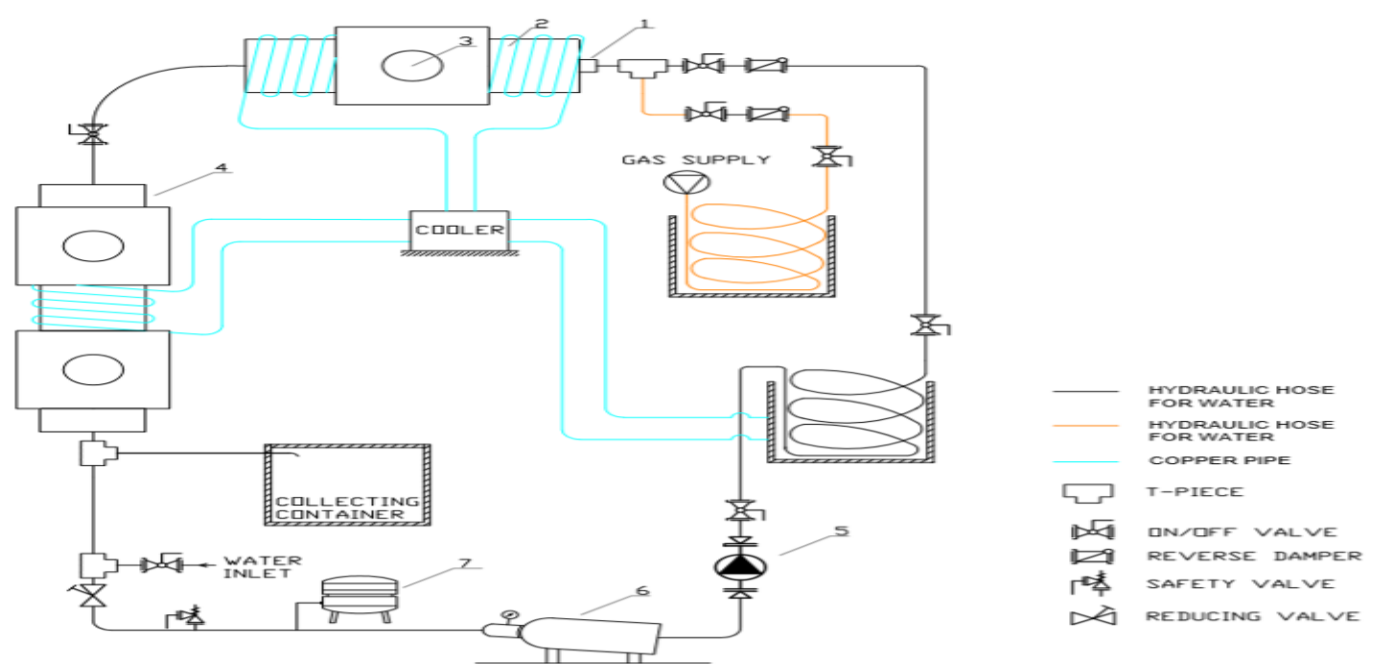

Figure 2: Schematic of experimental equipment

The experiment is carried out by first filling the entire system with water through the water inlet approximately halfway through the sapphire visor of the upper vessel. The plunger pump (5) will draw the water flowing out of the bottom vessel (4), which it will press to $25 \mathrm{MPa}$. The pipe for this circuit is wound into a spiral and placed in a plastic container. The vessel is connected to a cooling device which provides cooling of the water in the pipe after it has been pressed to a specified pressure. Symbols to the Figure 2 are in next table.

Table 1: Schematic positions on the experimental equipment.

\begin{tabular}{|l|l|l|}
\hline Symbol & Part of the device & Model $/$ type \\
\hline 1 & Nozzle & Spray angle $51^{\circ}$ and $155^{\circ}$ \\
\hline 2 & High pressure vessel VN 1 & $\varphi 175 / 146,9 \mathrm{~mm}, \mathrm{~m}=42 \mathrm{~kg}, 5,71$ \\
\hline 3 & Sapphhire visor & Normal $\varphi 50 \mathrm{~mm}$ \\
\hline 4 & High pressure vessel VN 2 & $\Phi 175 / 146,9 \mathrm{~mm}, \mathrm{~m}=73 \mathrm{~kg}$ \\
\hline 5 & Plunger pump & $\mathrm{P}=4,7 \mathrm{~kW}, \mathrm{Q}=5,1$ l.min-, $\mathrm{n}=1420$ ot.min-1 \\
\hline 6 & Accumulator & Volume 201, working pressure. 207 bar \\
\hline 7 & Expansion tank & Reflex-refix DT 80, working pressure 16 bar, \\
\hline
\end{tabular}


Water at $25 \mathrm{MPa}$ will flow through the hose, through the non-return valve towards the nozzle (1). On the other hand, the natural gas compressor (in our case a compressor is used, but a bottle of compressed methane can be used instead) will compress the natural gas a gas at a pressure of 25 $\mathrm{MPa}$, which will flow through a conduit which is coiled into a spiral and placed in a vessel which is connected to a cooler. The cooler is intended to cool the gas after it has been pressed to the desired temperature. The compressed gas will pass through the hose, through the non-return valve and the T-piece, where it will mix with the pressurized water and co-enter the nozzle (1). In the nozzle, a compressed mixture of water and natural gas is atomized into small particles, whereby it will be possible to better bond the natural gas to the intermolecular structure of the water and subsequently to form various forms of hydrate. The water / natural gas mixture should initially flow from the vessel through the pipe to the high-pressure vessel after it is filled. After filling the high-pressure vessels with the gas / water mixture to the visible area, which can be seen through the sapphire visors, the shut-off valve is closed. From that moment on, the seeds of the hydrate will be formed and the time after the formation of the hydrate will be measured. It will be possible to observe the formation of natural gas hydrates through the said sapphire visors. The pressure is up to $25 \mathrm{MPa}$ in the whole plant.

\section{Simplified Numerical Simulation}

Simulation of gas hydrate preparation processes in MatLab environment using block library Thermolib gives many various opportunities to create very useful models. There are countless possibilities of setting individual block components as well as the medium itself. The numerical model can be used for many applications. In our work we focused on exploring various options of involvement and use of this numerical method to describe proposed gas hydrate formation system.

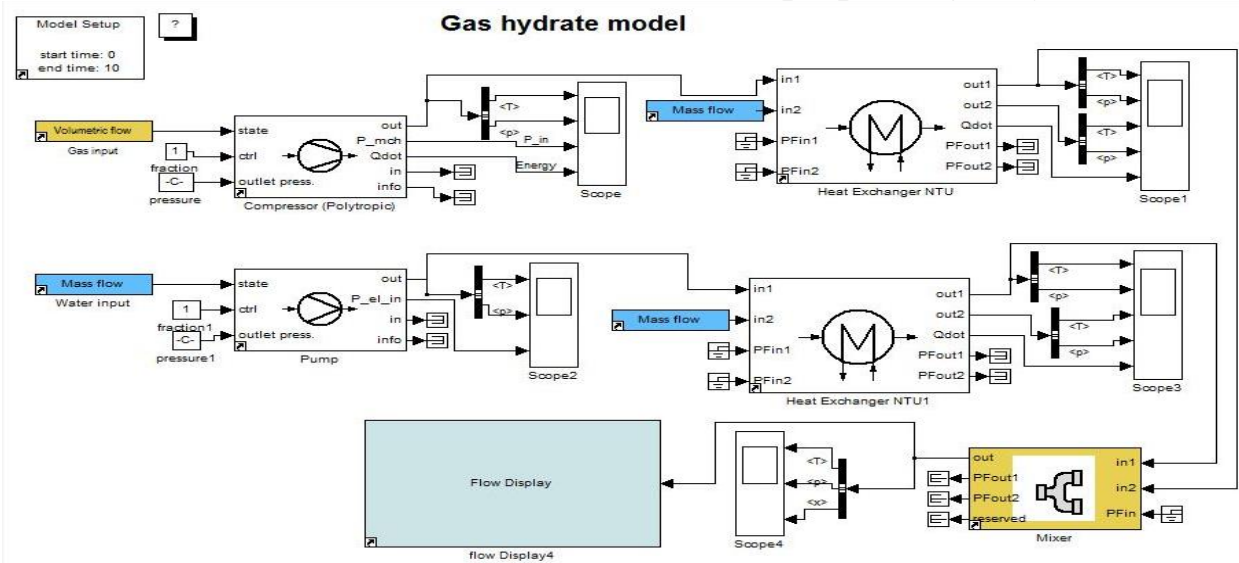

Figure 3: Simplified numerical model

\section{Conclusion}

The water with the gas will be mixed in the pipeline just prior to the inlet of the first $5,70 \mathrm{dm}^{3}$ main pressure vessel (TN1) where it will be in the 1/150 to 1/170 ratio. Water will be sprayed through the nozzle into that pressure vessel. By spraying the liquid onto small particles, we want to facilitate the process of closing the gas into the water grid. In the design we consider two alternatives - nozzles with a spray angle of $55^{\circ}$ and $150^{\circ}$. We assume that in practice, a solution with a greater spray angle will prove as more effective because it can cover a wider area with small water particles. 
At low, but still over-temperature and above $6 \mathrm{MPa}$, we assume the formation of crystalline water grids that form a cage around small gas particles. Gas in this process will significantly reduce its volume.

The resulting methane hydrates should then be directed to another $15 \mathrm{dm}^{3}$ (TN2) pressure vessel. Place a micron screen with a $25 \mu \mathrm{m}$ mesh density in it to collect them through blind flanges on the container will be also a suitable solution.

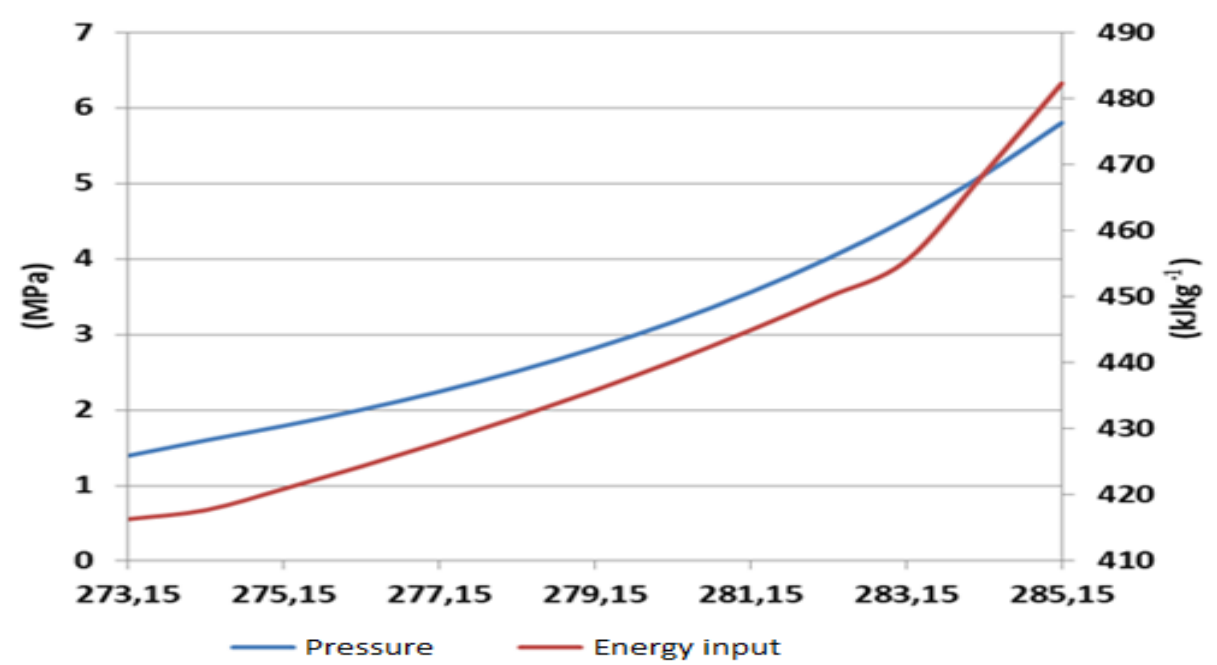

Graph 4: Pressure needed to produce methane hydrates and energy input

Work on article has been financially supported by the project VEGA-1/0738 / 18 „Optimization of energy inputs for the rapid generation of natural gas and biomethane hydrates for the accumulation of high potential primary energy" and the project KEGA-063ŽU-4/2018 „Depositing hydrocarbon gases into hydrate structures as an alternative energy storage method.“ The project is co-financed by EU funds. Project title: "Research on new methods of heat conversion from RES to electricity using new progressive thermal cycles" ITMS 26220220117

\section{References}

[1] DEMIRBAS, Energy Conversion and Management, 51, 7, (2010).

[2] V. FOLTIN, J. RAJZINGER, M. JURIGA, Š. GUŽELA, "Nové zdroje zemného plynu: bridlicový plyn a zemný plyn viazaný v hydrátoch," in Zbornik prednášok z 21. Medzinárodnej konferencie Vykurovania, edited by SSTP, (SSTP, Bratislava, 2013), pp. 73-76.

[3] E. S. HARRISON, Natural Gas Hydrates," in Submitted as course fo Physics 240, Stanford University, Fall (2010).

[4] M. MASLIN, Gas hydrates: past and future geohazard? vol. 368, issue 1919, (2010).

[5] K.A. KVENVOLDEN, G.D. G.D. GINSBURG,V.A. SOLOVIEV, Worldwide distribution of subaquatic gas hydrates, Geo-Marine letters, vol. 13, issue 1.p. 32-40. (1993)

[6] J. SIAŽIK, M. MALCHO, R. LENHARD. "Proposal of experimental device for the continuous accumulation of primary energy in natural gas hydrates," in EPJ Web Conferences 143, 02106 (2016)

\footnotetext{
*Corresponding author.

E-mail address: peter.durcansky@ fstroj.uniza.sk
} 